\title{
25742 \\ From On-Orbit to Offshore: Shared Challenges, Collaborative Solutions
}

\author{
Gianluca Callini \\ JACOBS
}

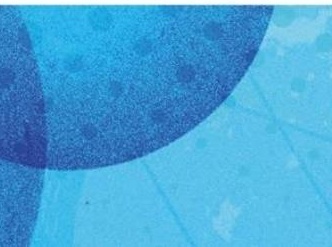




\section{Agenda}

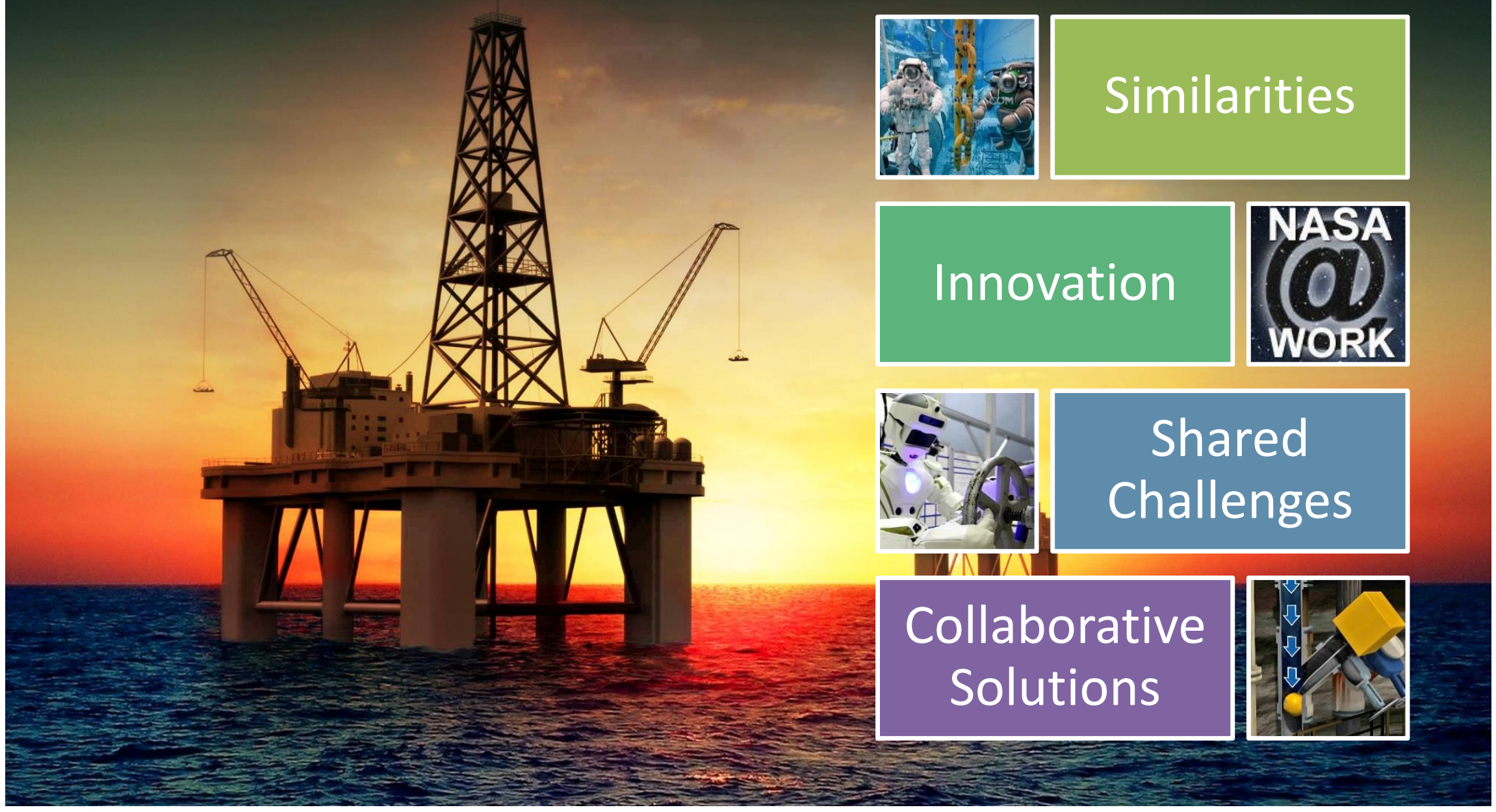




\section{Agenda}

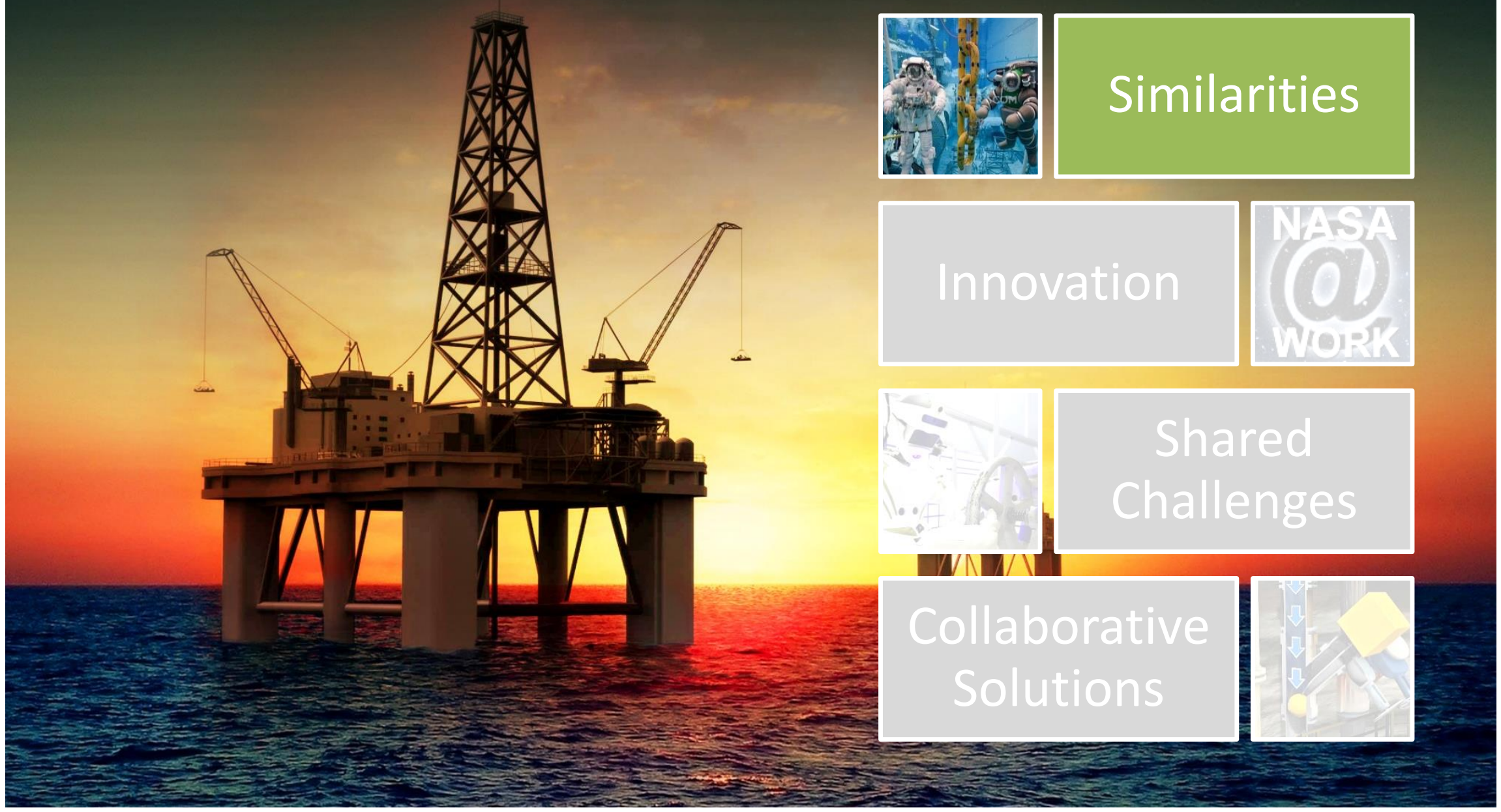




\section{Similarities Space and Offshore Environments}

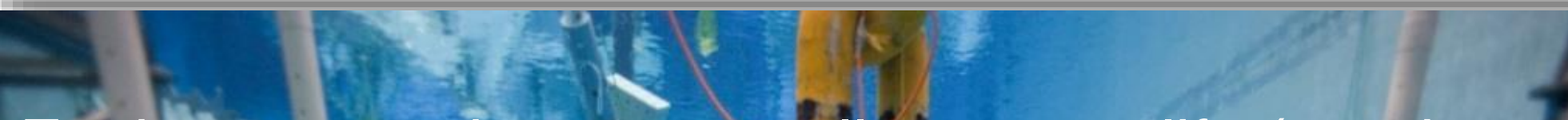

Environments do not naturally support life (requires life support)

Extreme temoeratuce ranges

Pressurizerà Systems

Remote operations operations

Hazardous operätions requining very specific training 


\section{Agenda}

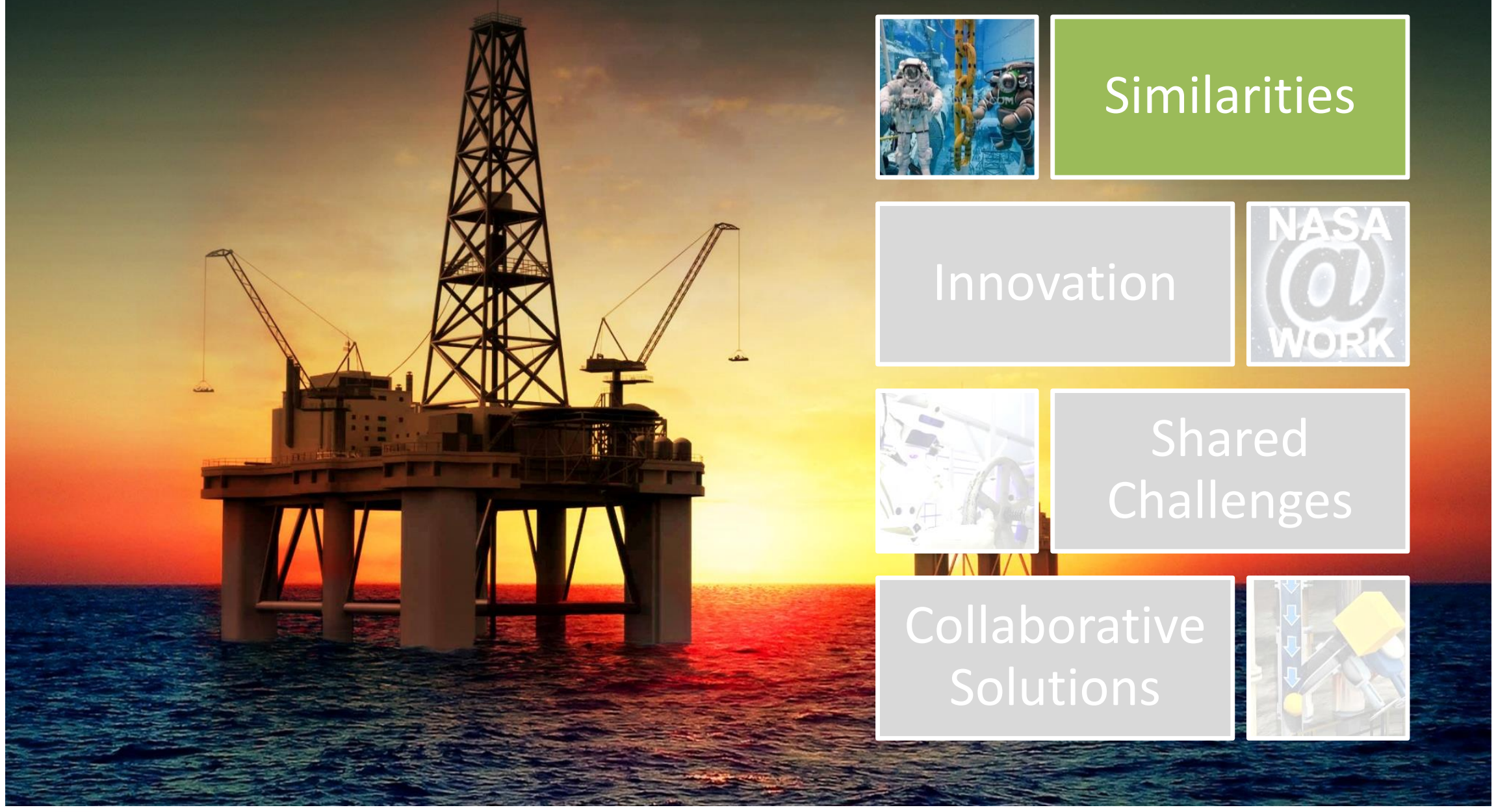




\section{Agenda}

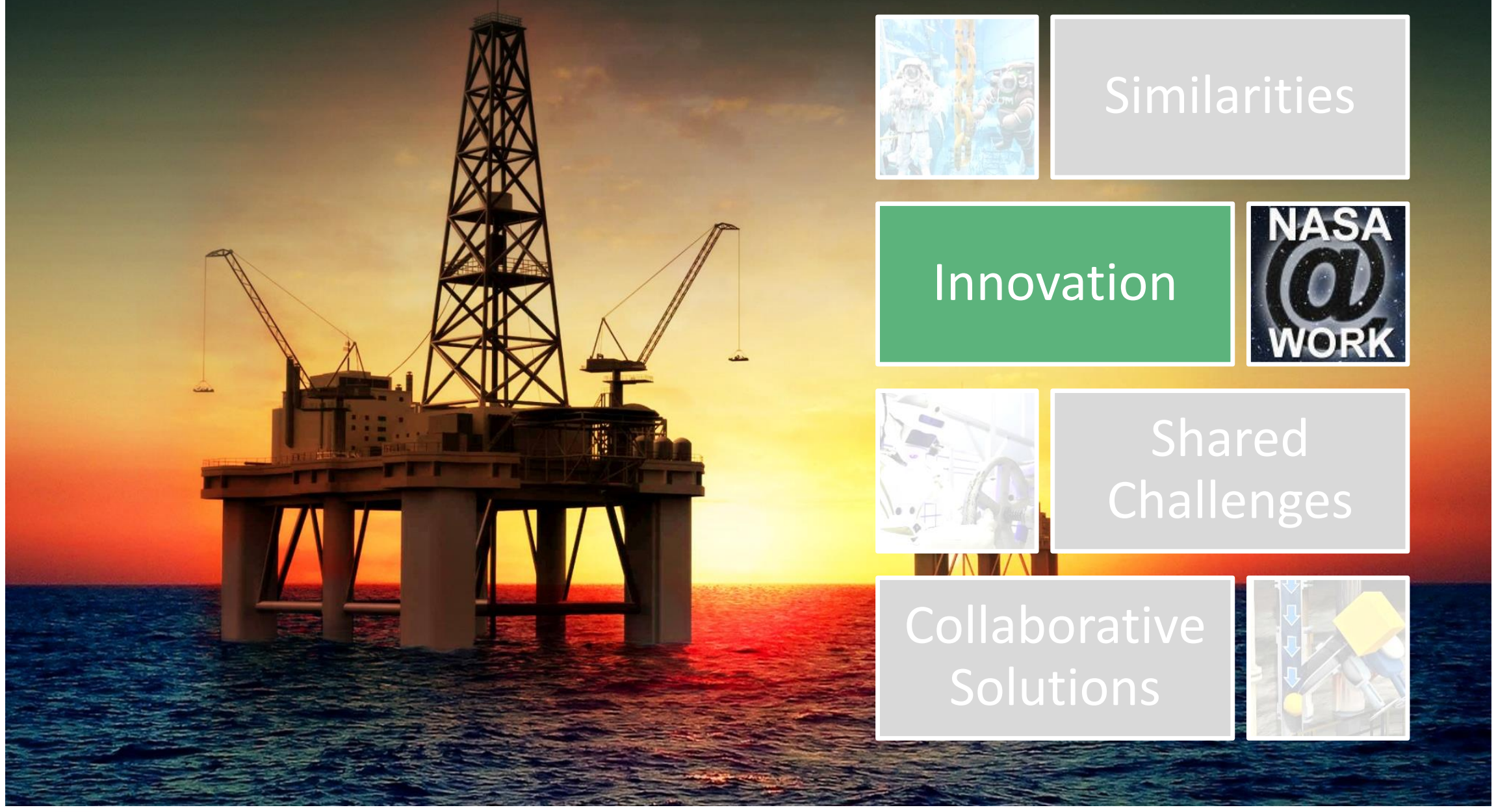




\section{Open Innovation @ NASA}

\section{Center of Excellence for} Collaborative

Innovation

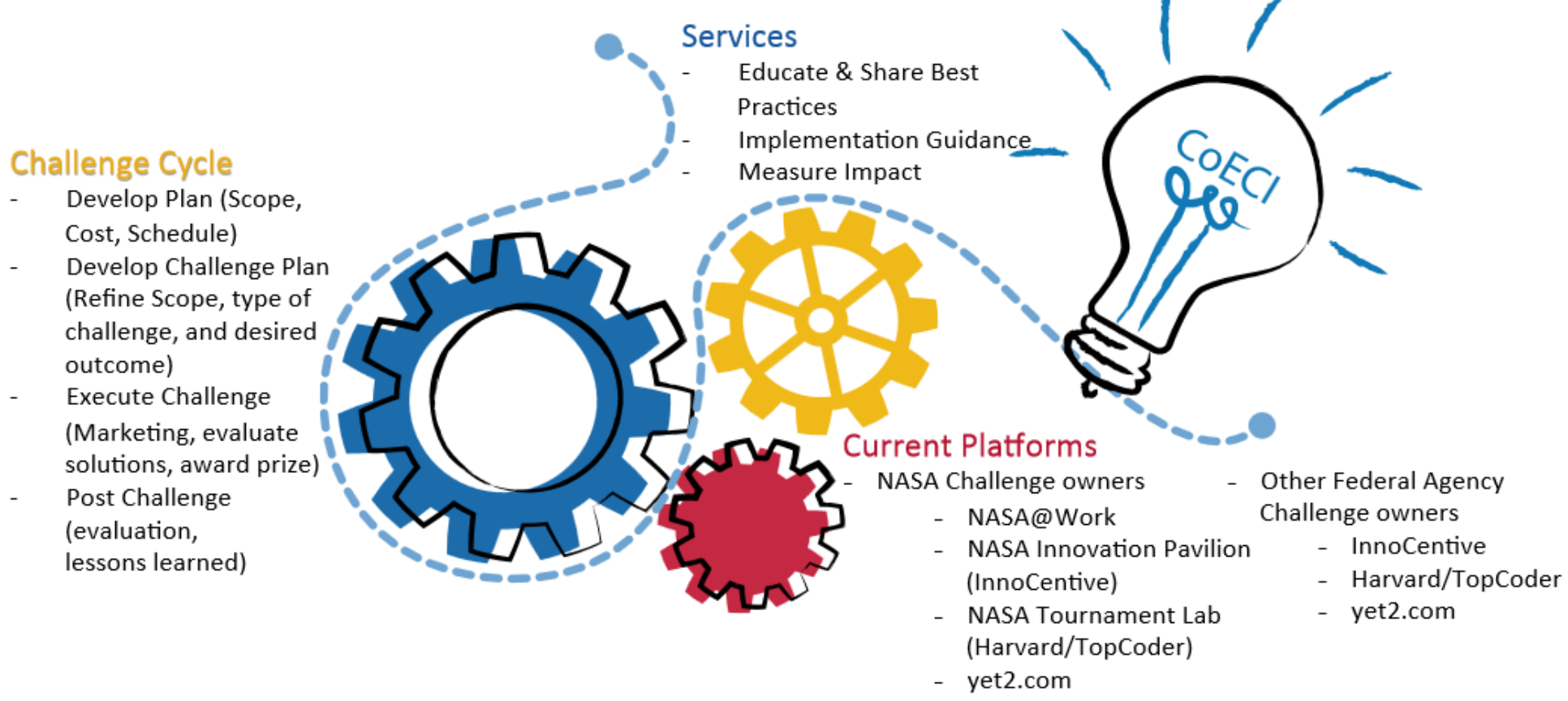

\section{OTC2015}




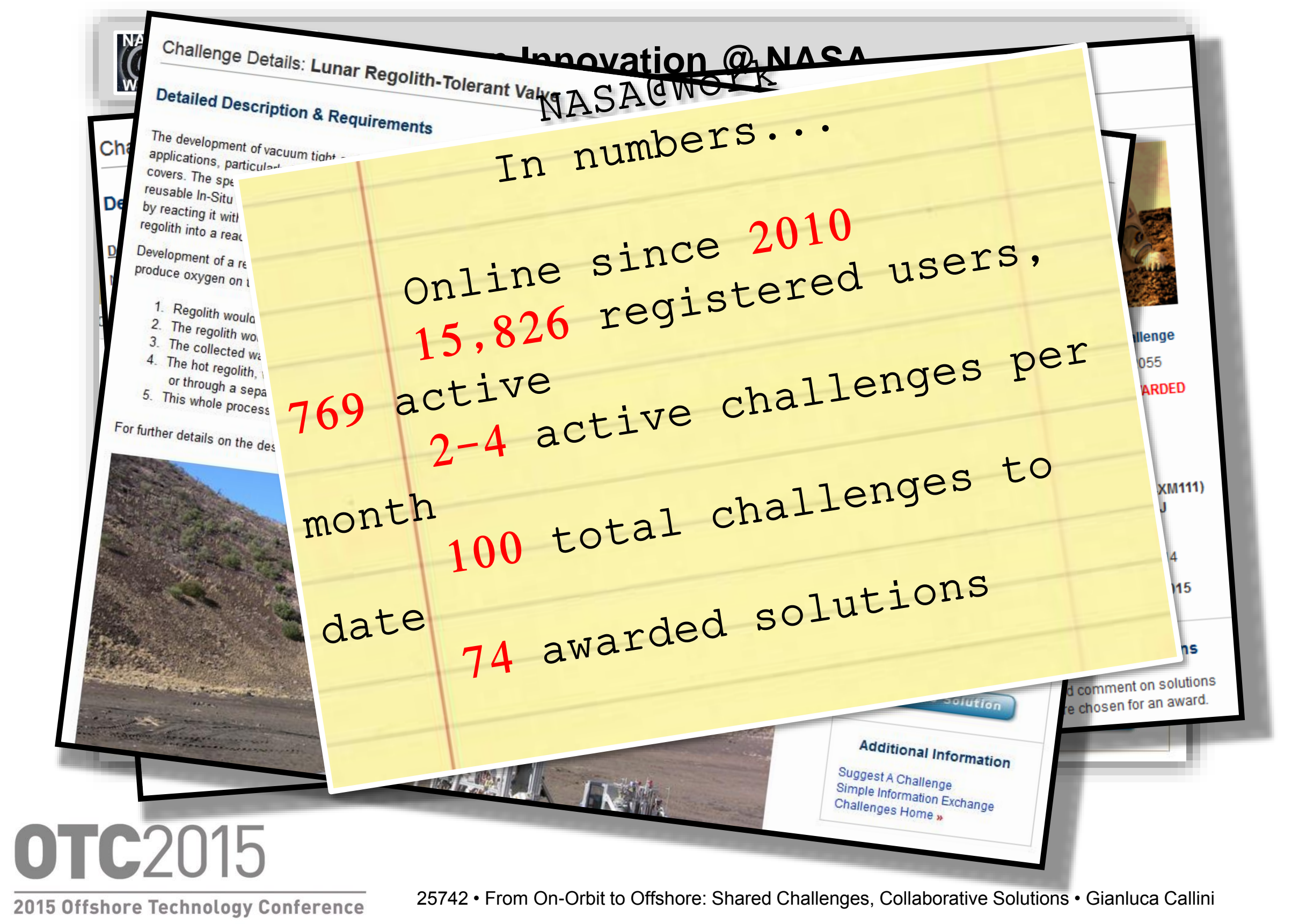




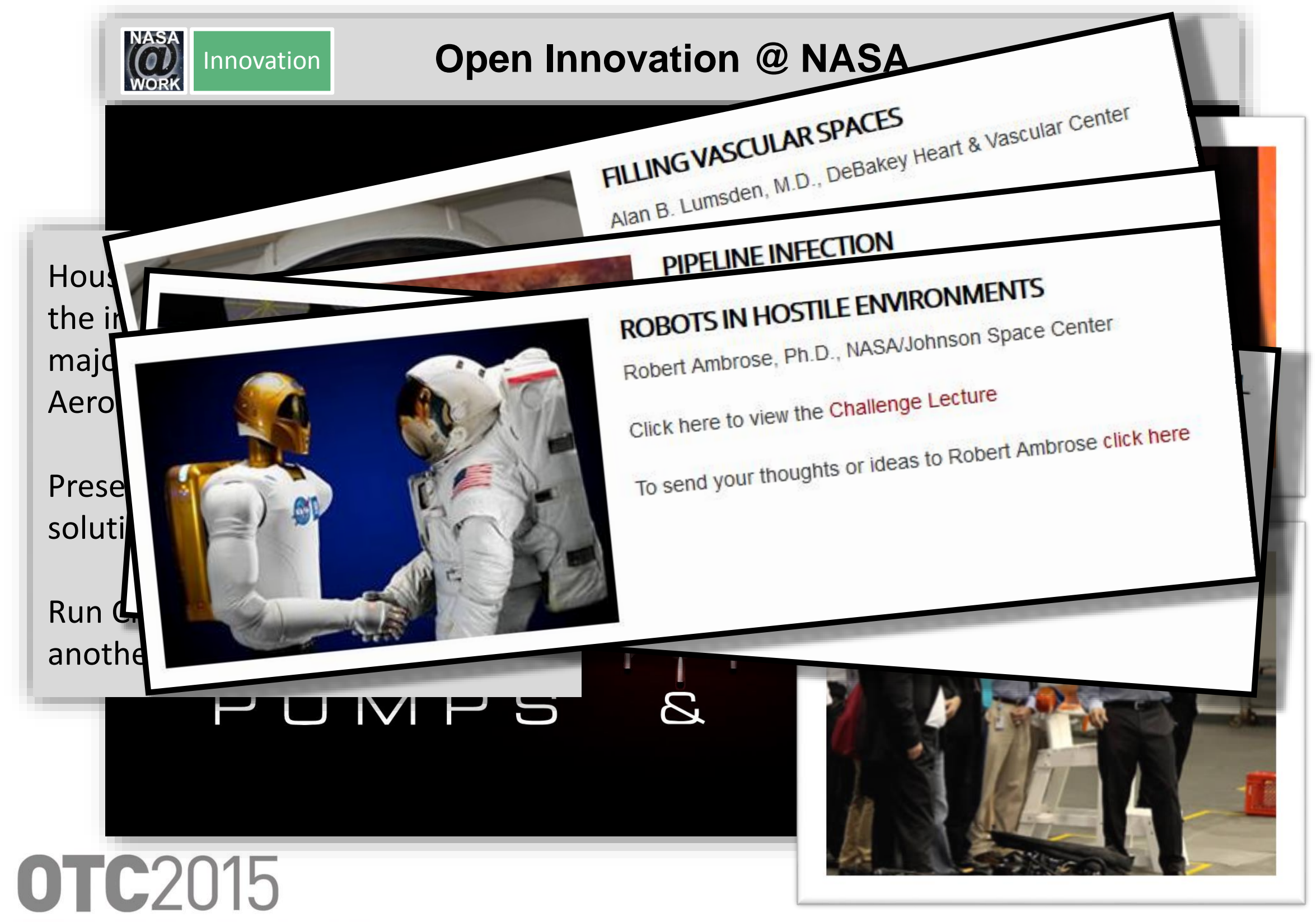




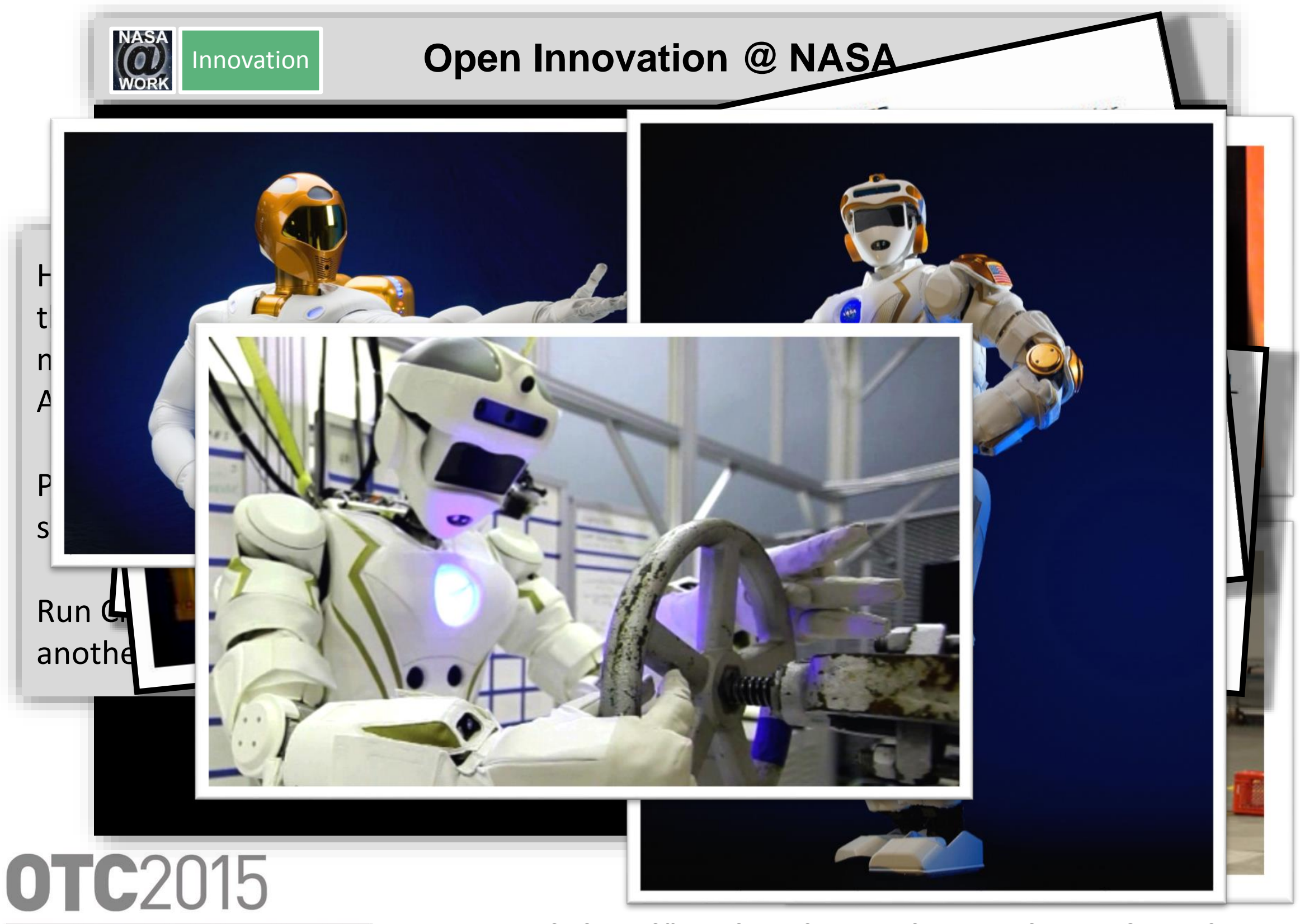




\section{Agenda}

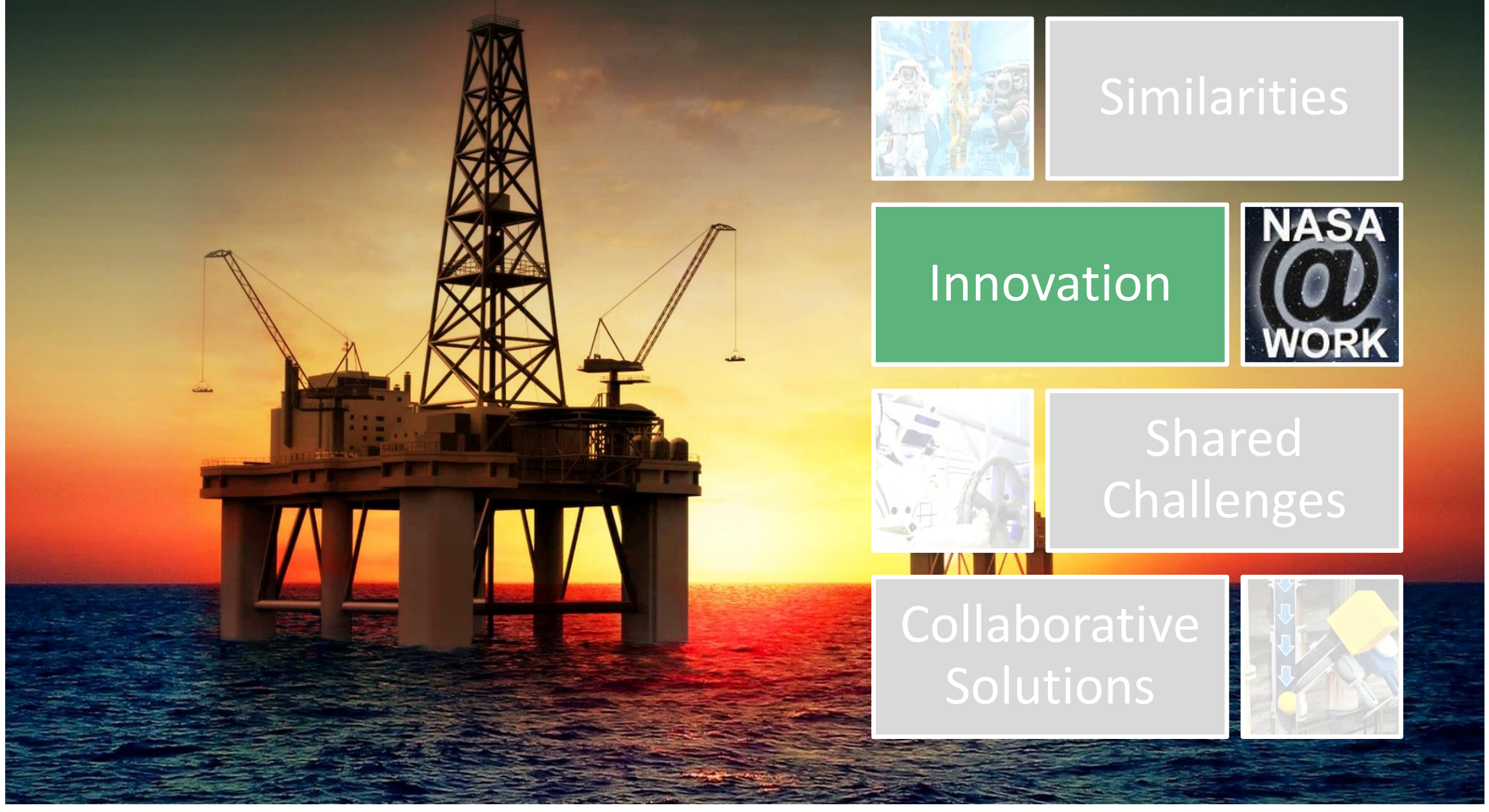




\section{Agenda}

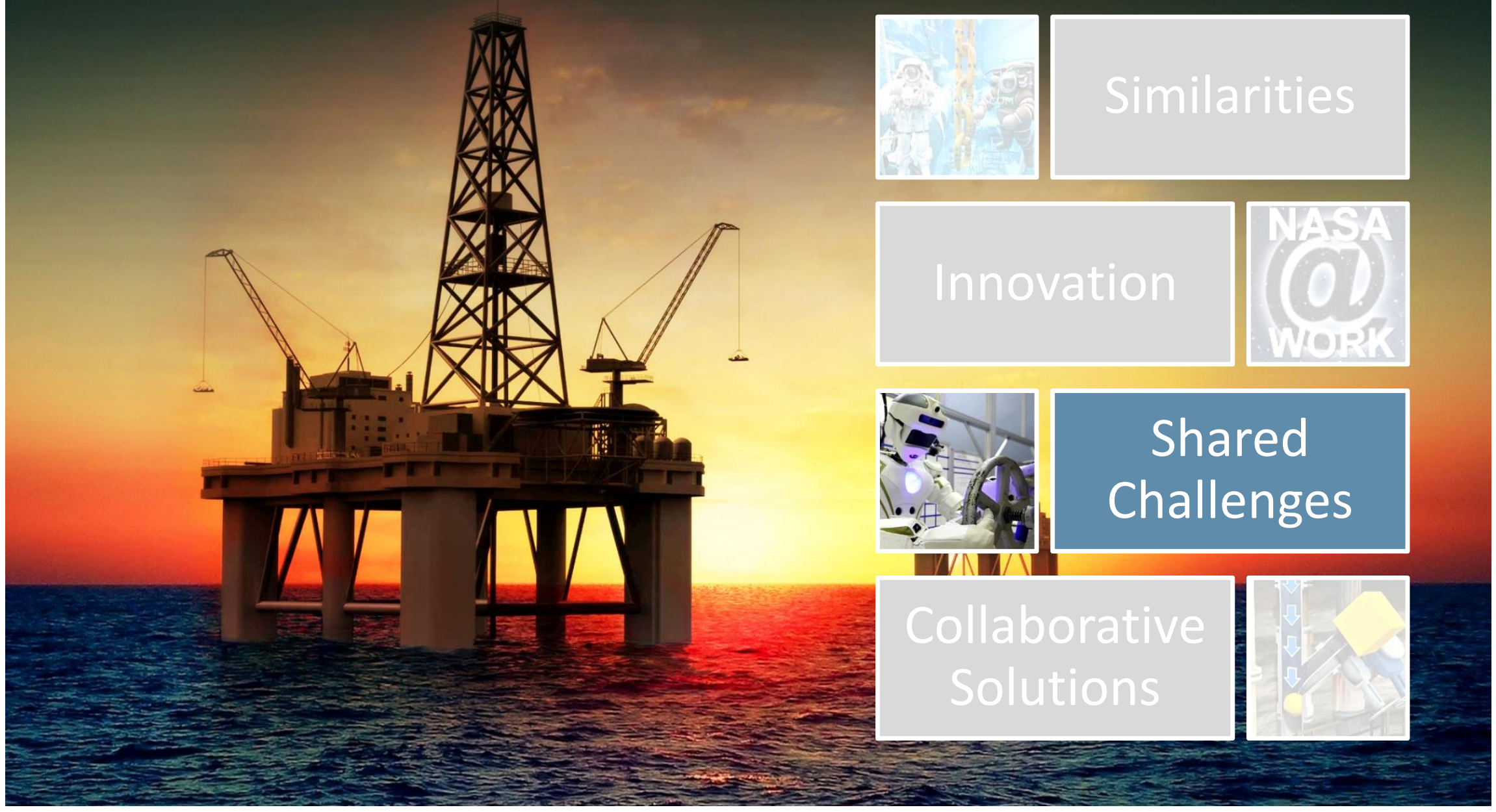




\section{Shared Challenges}

\begin{tabular}{|c|c|}
\hline Areas & Challenges \\
\hline Crew and Thermal Systems & $\begin{array}{l}\text { Life support systems and thermal control } \\
\text { systems in extreme environments } \\
\text { (pressure, thermal, rente, }\end{array}$ \\
\hline $\begin{array}{l}\text { Aerosciences and Flight } \\
\text { Mechanics }\end{array}$ & $\begin{array}{l}\text { Mission design, risk mitigal on; software } \\
\text { reliability and safety. }\end{array}$ \\
\hline Propulsion and Power & $\begin{array}{l}\text { Safer battery technologies in extreme } \\
\text { environments. }\end{array}$ \\
\hline $\begin{array}{l}\text { Software, Robotics, and } \\
\text { Simulation }\end{array}$ & $\begin{array}{l}\text { Assist/Augment humans; take humans } \\
\text { place in hazardous situations; } \\
\text { teleoperation/telepresence. }\end{array}$ \\
\hline Structures & Lighter, human-rated composite structures. \\
\hline Avionics & $\begin{array}{l}\text { Autonomous guidance, navigation and } \\
\text { controls; RFID asset management; human } \\
\text { interface systems. }\end{array}$ \\
\hline
\end{tabular}




\section{Agenda}

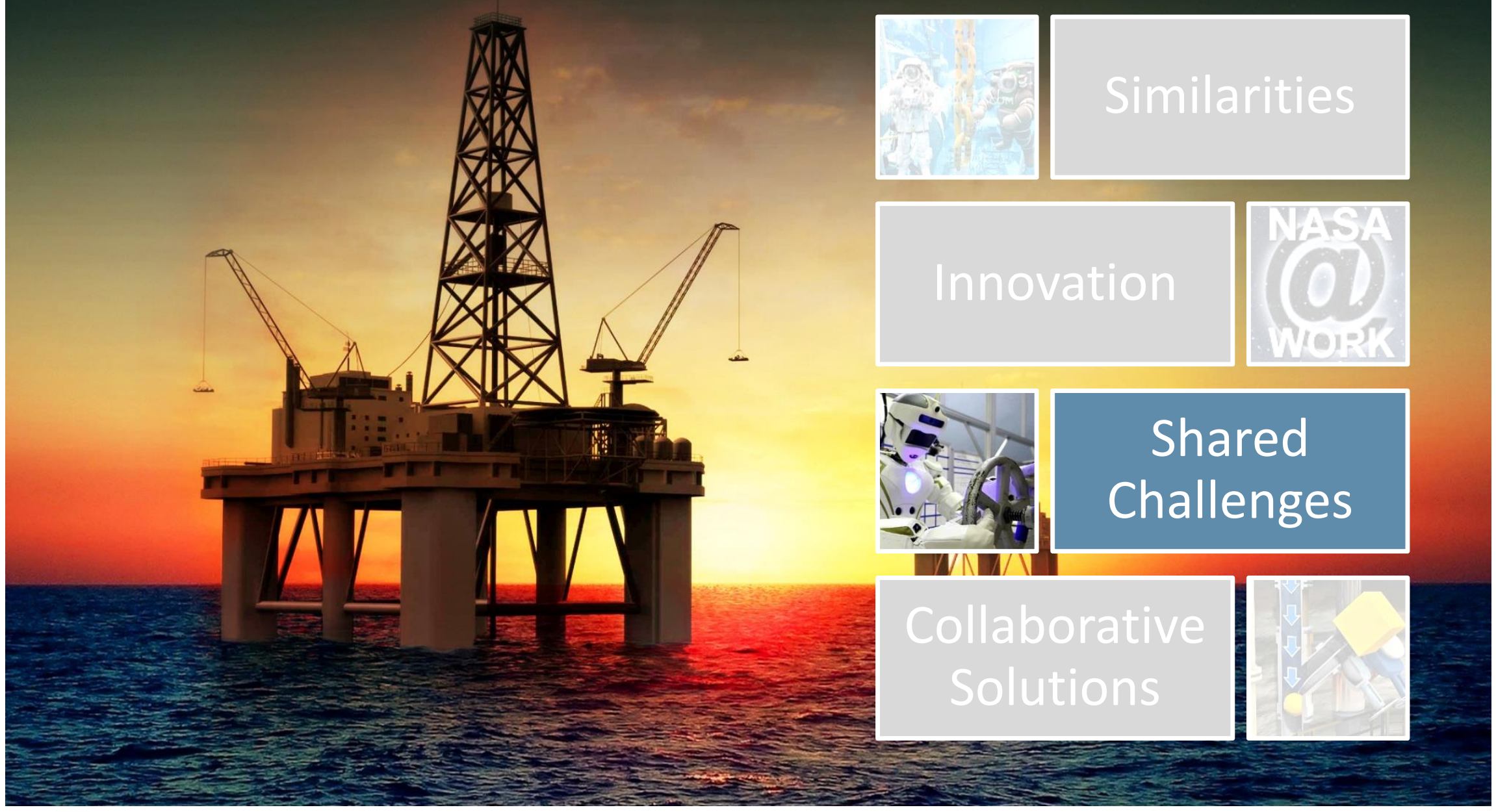




\section{Agenda}

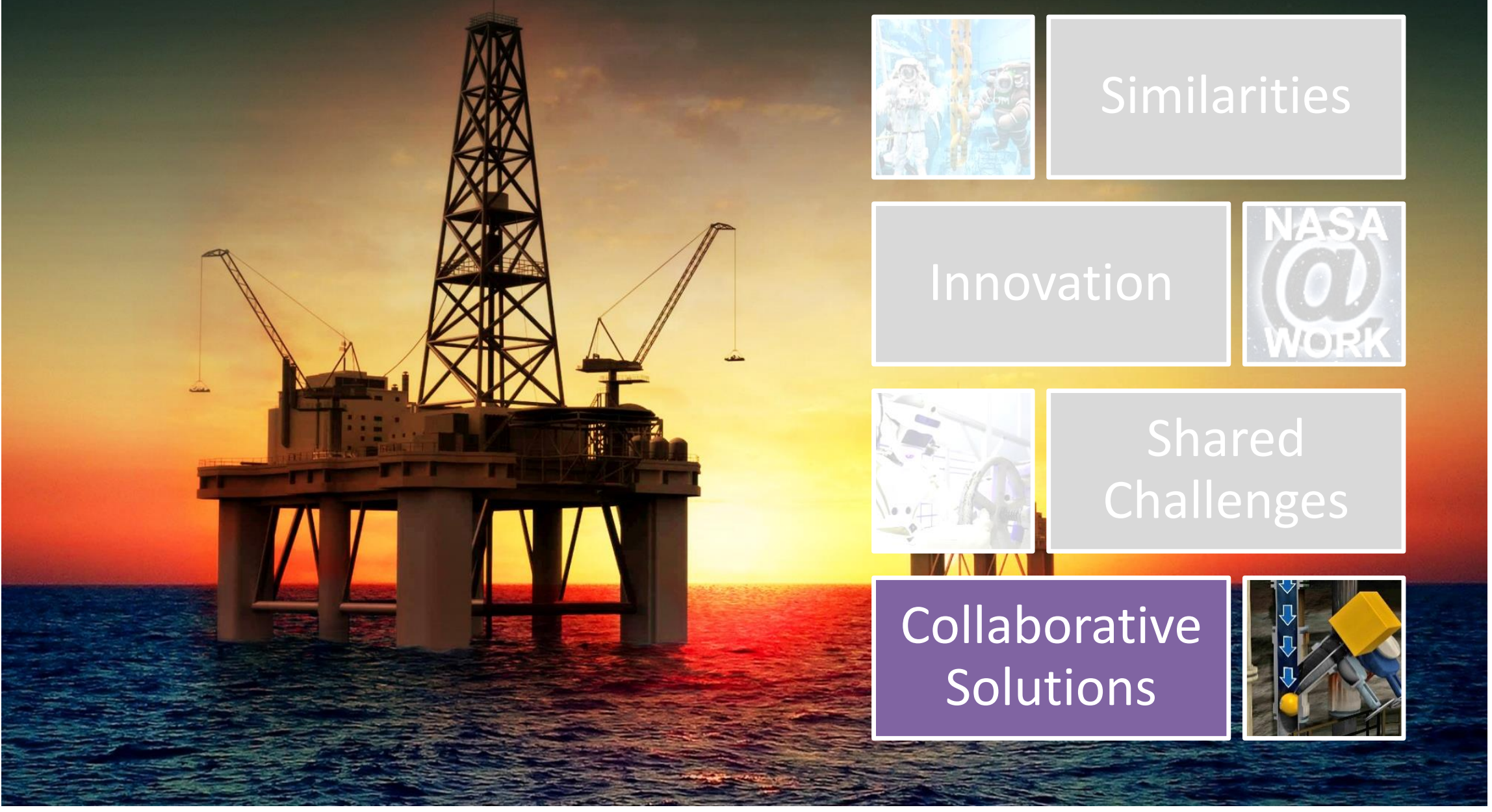




\section{Collaborative Solutions}

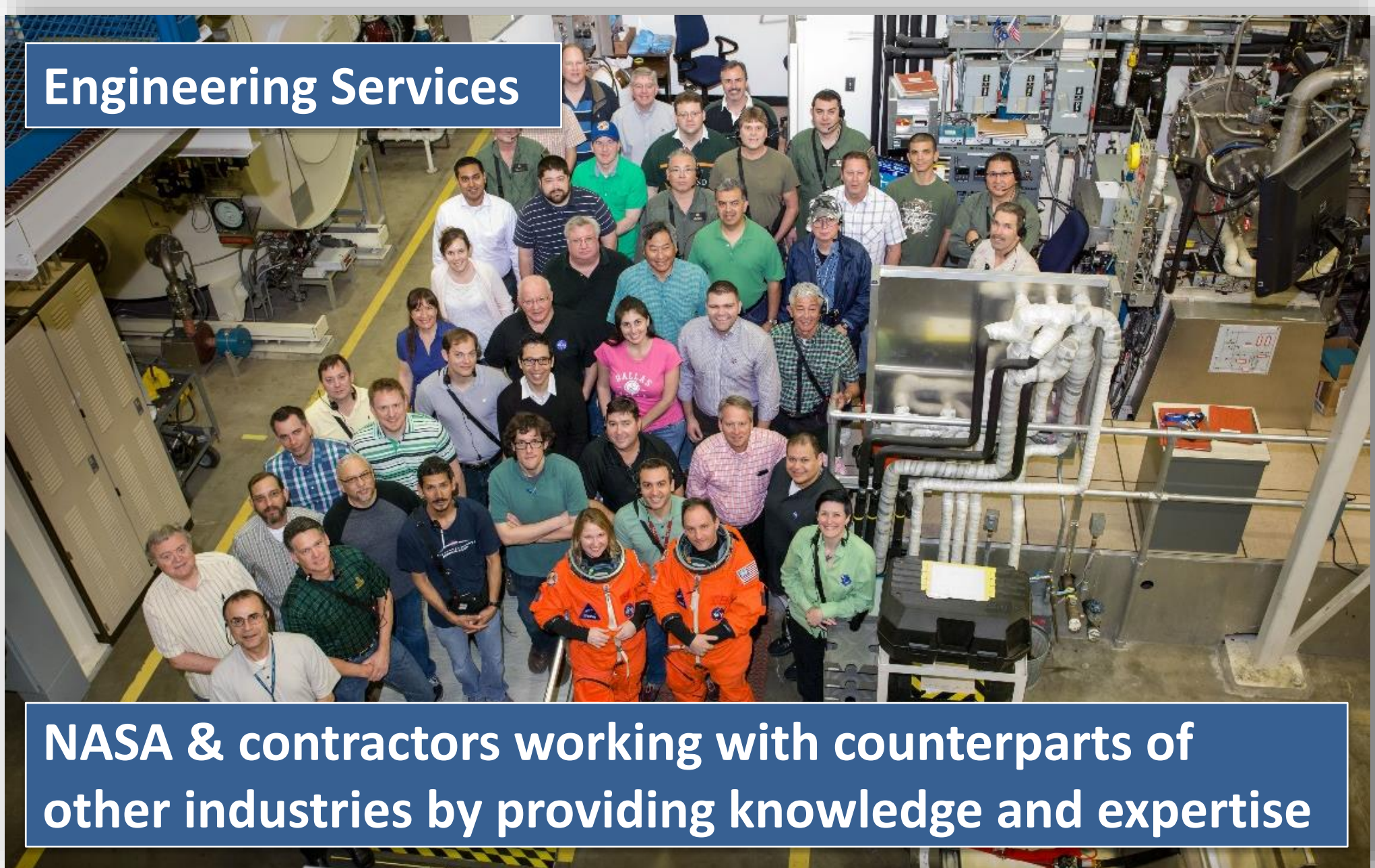




\section{Collaborative Solutions}

\section{Environmental Analogs}

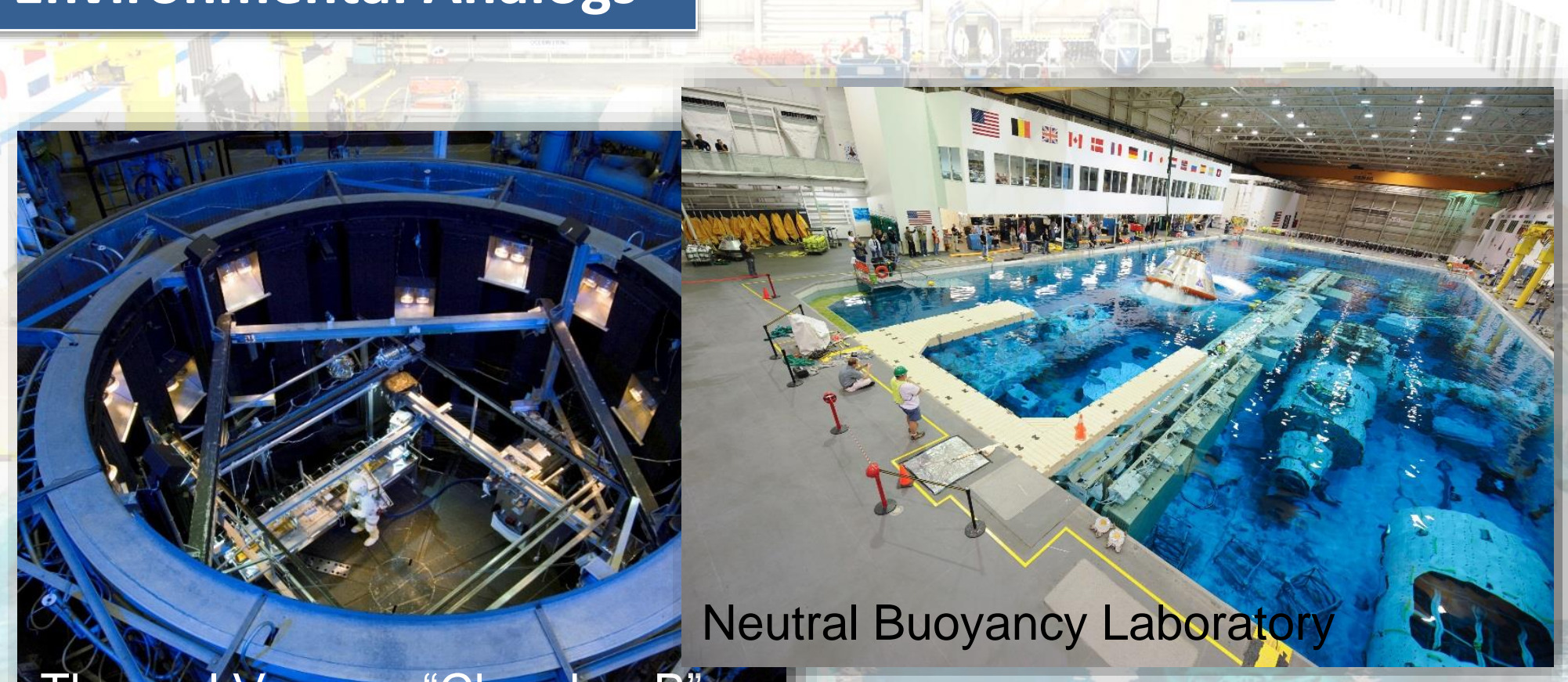

\section{Thermal Vacuum "Chamber $B$}

Repurposing/adapting space simulation test facilities (e.g. thermal/thermal-vacuum, weightlessness) for training and testing. 


\section{Collahorative Solutions}

Hazardous Operations

The Customer cycle, on either a stand-alone or integr to a customer's needs.
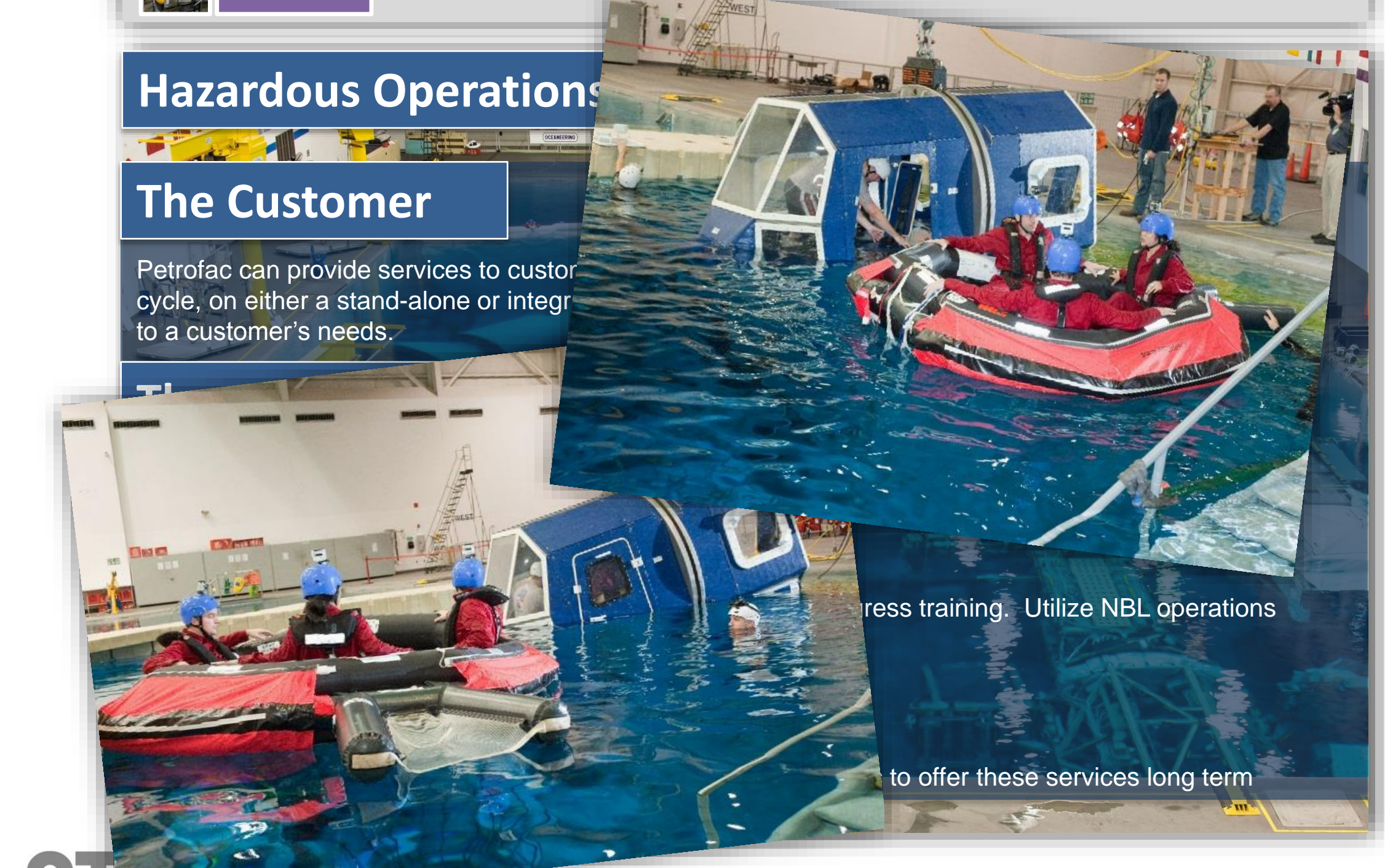


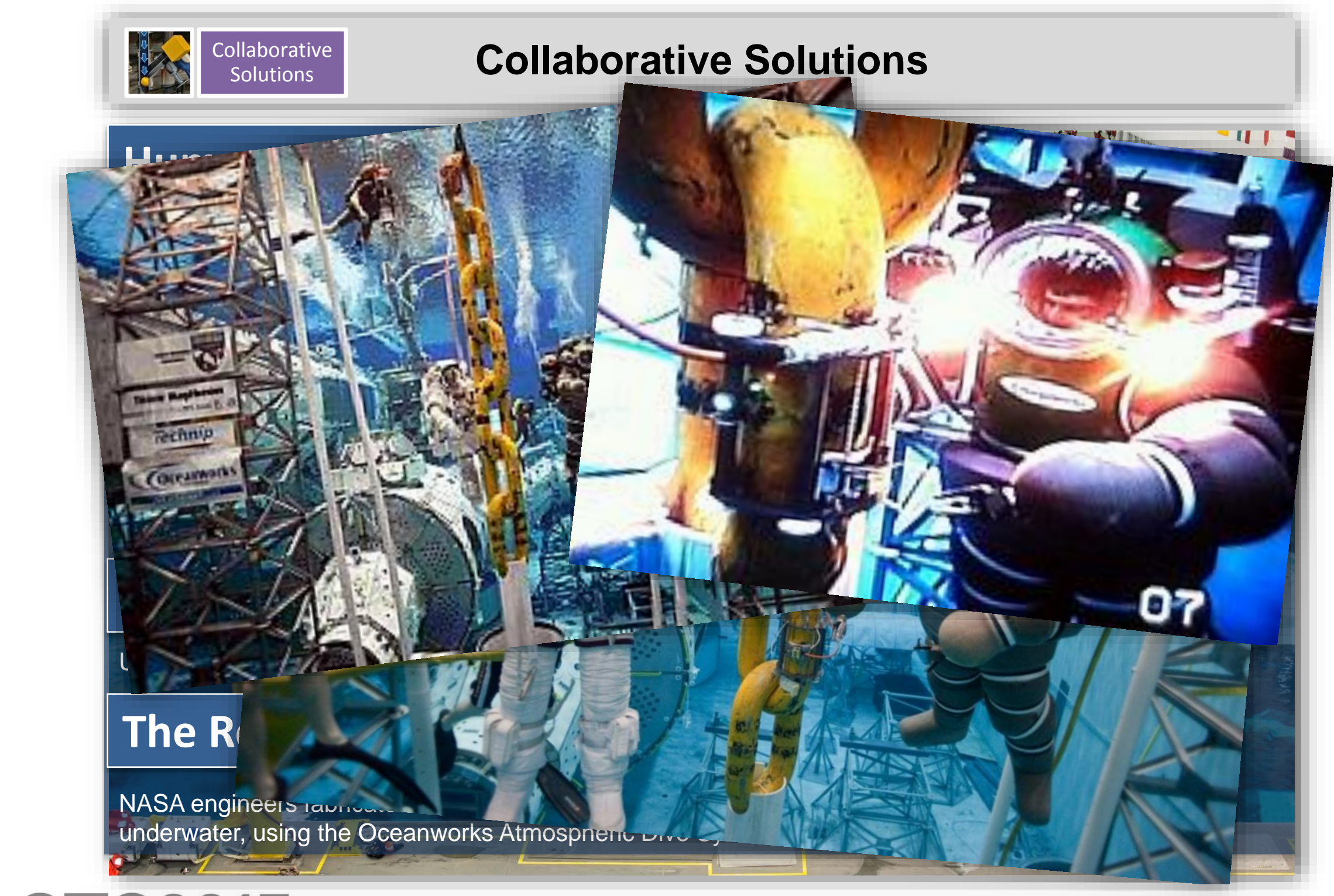




\section{Collaborative Solutions}

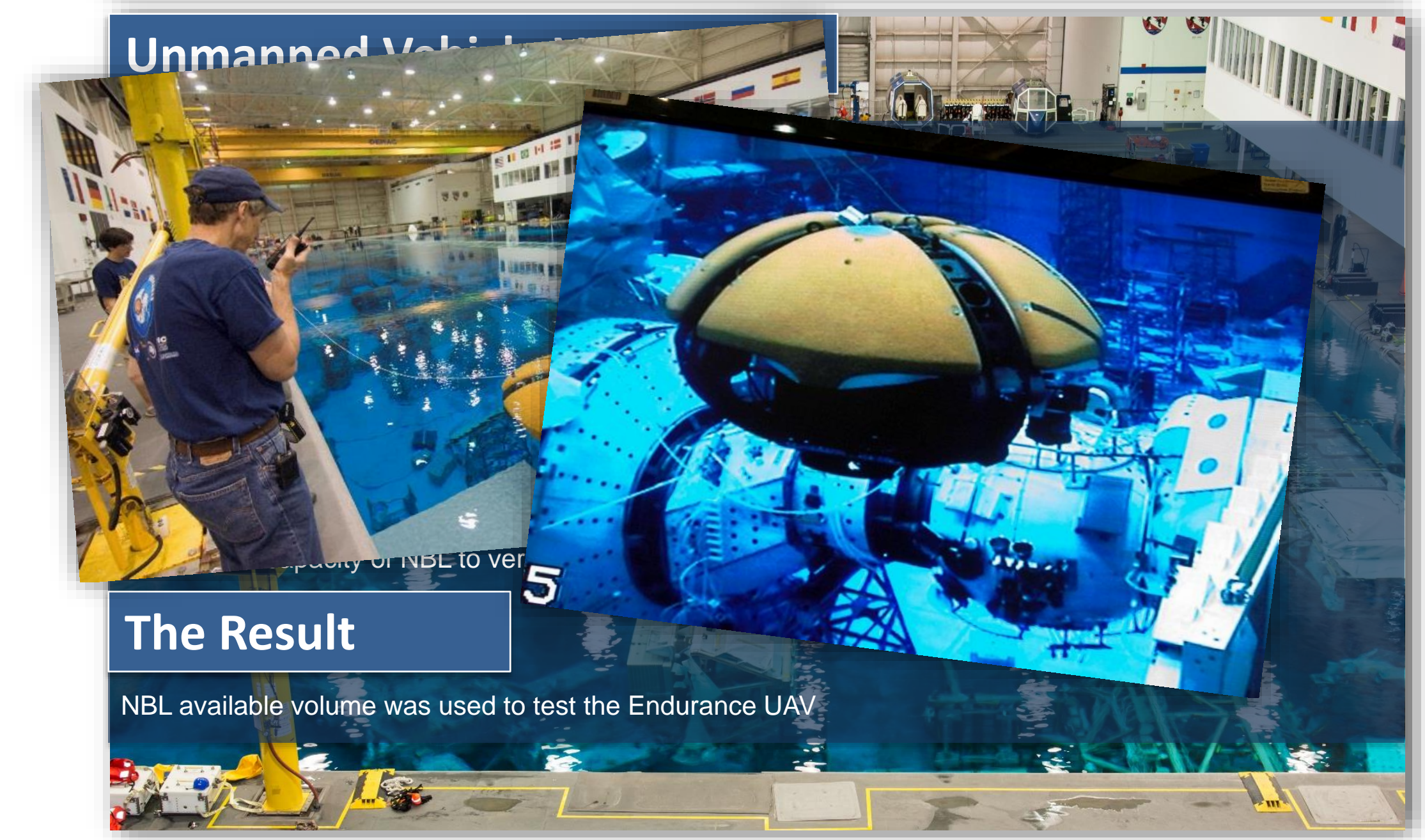




\section{Collaborative Solutions}

\section{Hardware Developmant \\ Tension Leg Platform}

The Curtam

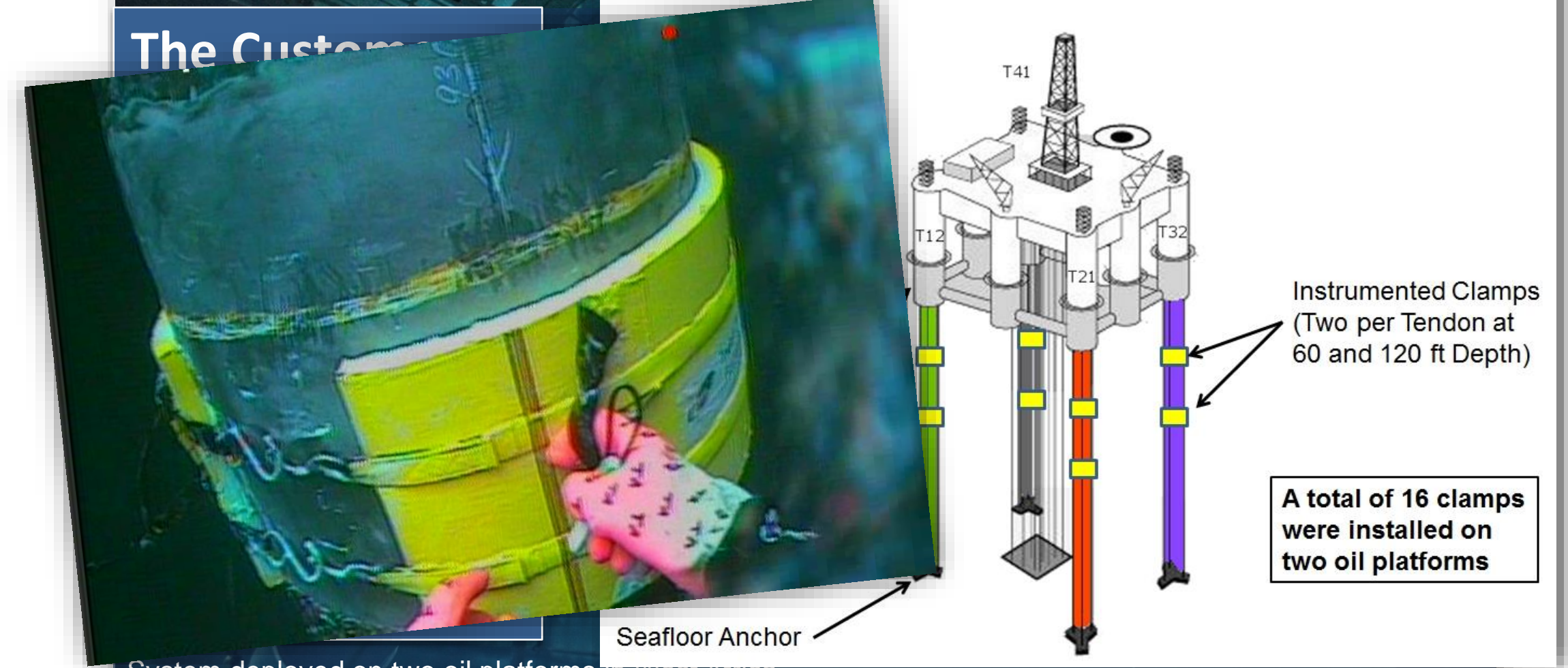

System deployed on two oil platforms in vvest Anncea

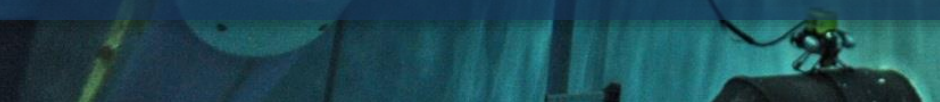




\section{Collaborative Solutions}

\section{Hardware Developmi}

\section{The Customer}

Major oil and gas common
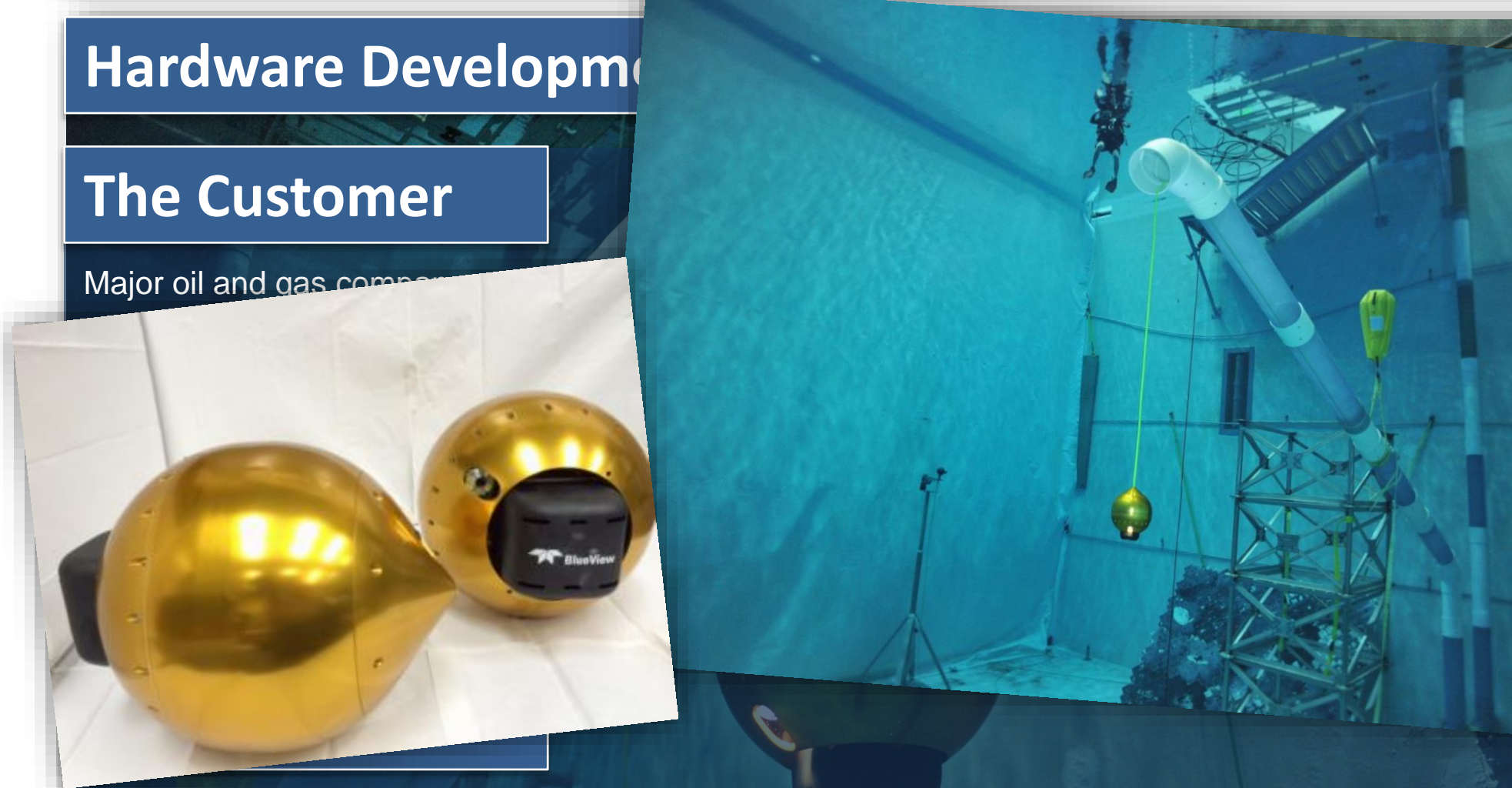

Using some technologies developed for a prior extravehicular camera, built, test and delivered sensor spheres. Tested at NBL and at remote oil platforms.

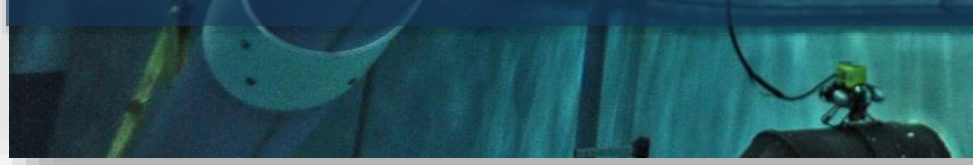




\section{Conclusion}

Today's NASA is in a very different environment than at its inception

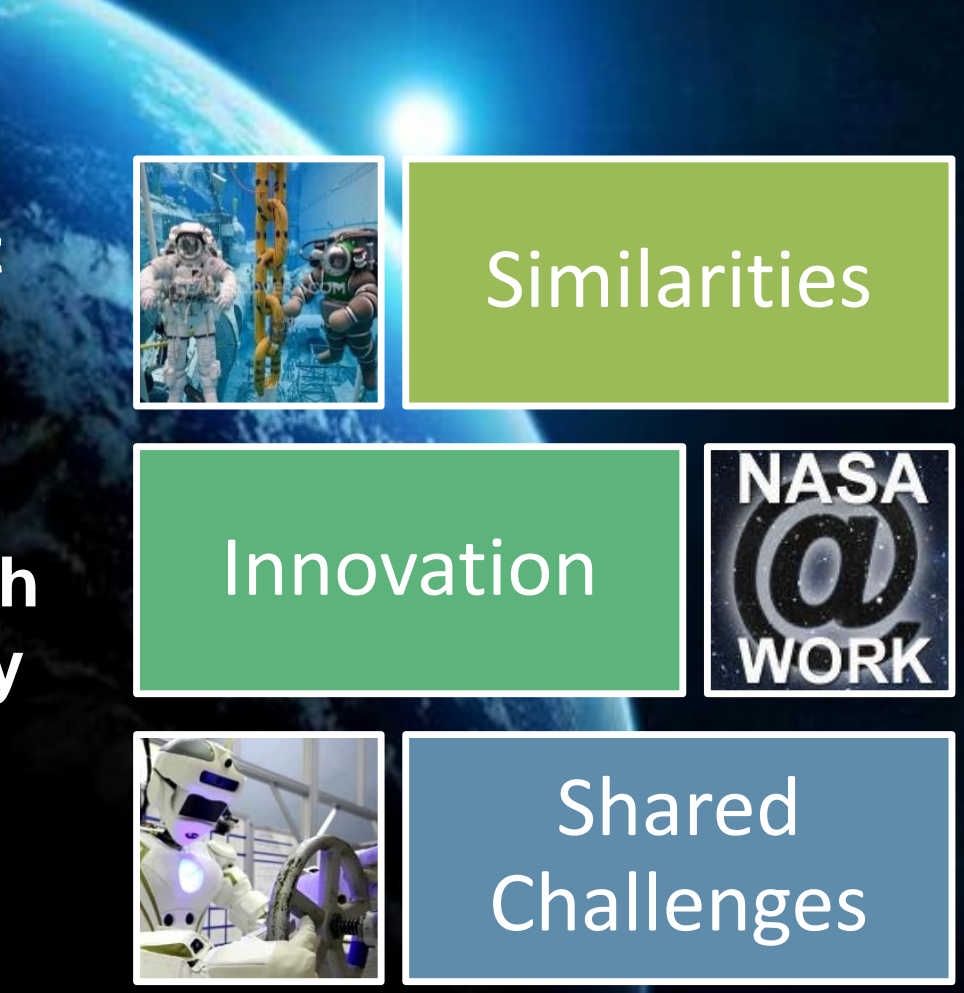

Agency is transforming to become lean and more adaptive to innovate and collaborate

\section{Collaborative Solutions}

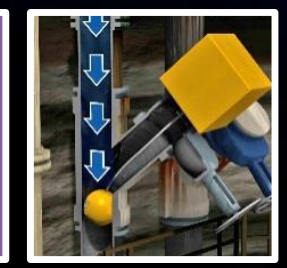




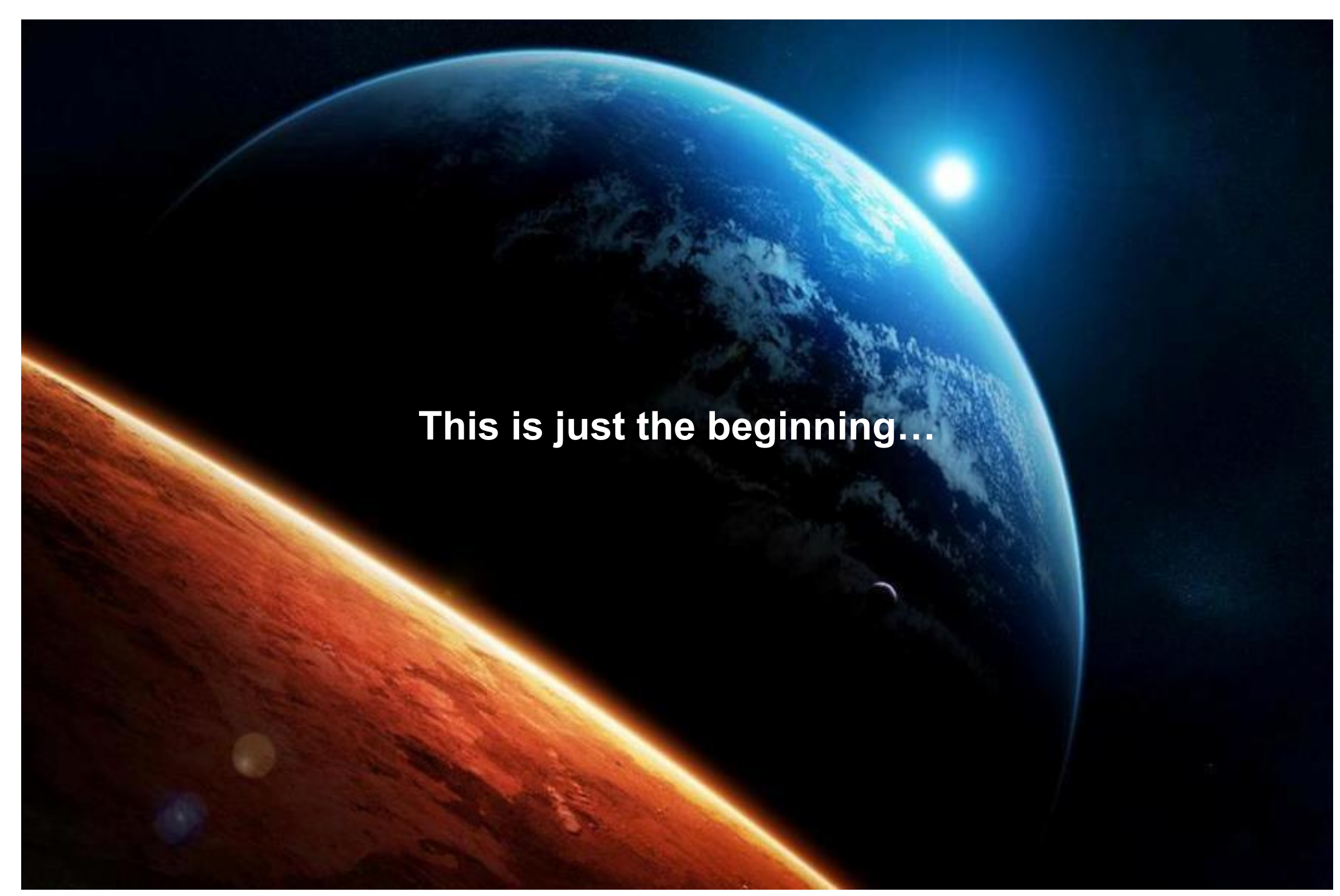




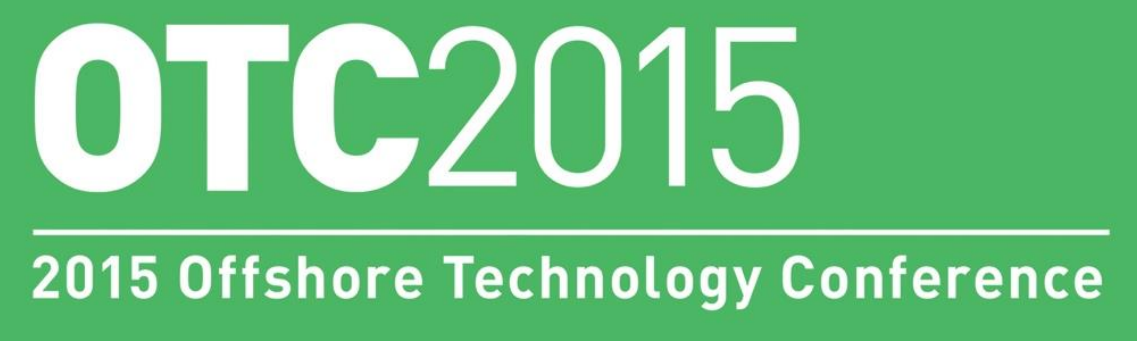

\section{4-7 May 2015 \\ HOUSTON, TEXAS, USA}

\section{Acknowledgements / Thank You / Questions}

